Intravenous immunoglobulin treatment in a type 3 von

Willebrand disease patient with alloantibodies and a

life-threatening gastrointestinal bleed

\title{
Nummi, Vuokko
}

2019-07

Nummi , V , Lehtinen , E , Mäkipernaa , A , Szanto , T \& Lassila , R 2019 , ' Intravenous immunoglobulin treatment in a type 3 von Willebrand disease patient with alloantibodies and a life-threatening gastrointestinal bleed ', Haemophilia, vol. 25 , no. 4 , pp. E291-E293 . https://doi.org/10.1111/hae

http://hdl.handle.net/10138/312946

https://doi.org/10.1111/hae.13765

draft

Downloaded from Helda, University of Helsinki institutional repository.

This is an electronic reprint of the original article.

This reprint may differ from the original in pagination and typographic detail.

Please cite the original version. 


\section{Intravenous immunoglobulin treatment in a type 3 von Willebrand disease patient with alloantibodies and a life-threatening gastrointestinal bleed}

\section{Dear Editor,}

Alloantibody development against von Willebrand factor (VWF) is a rare treatment complication in von Willebrand disease (VWD). Alloantibodies have been encountered mainly in type 3 , the most severe form with absent VWF, and particularly in null mutation cases. ${ }^{1}$ Patients who develop alloantibodies become suddenly unresponsive to VWF therapy. Re-exposure to VWF-containing products can also induce immune complex-mediated complement activation and life-threatening anaphylactic reactions. ${ }^{2}$ Intravenous immunoglobulin (IVIG) is used in acquired von Willebrand syndrome (AVWS), but there is lack of data of IVIG treatment in inherited VWD-associated alloantibodies. ${ }^{3}$ Here, we report a case of a 49 -year-old woman with type 3 VWD and VWF alloantibodies. Our management of her lifethreatening gastrointestinal (GI) bleed succeeded by co-administration of IVIG with VWF replacement.

Our patient had extended mucocutaneous bleeds postnatally and was diagnosed at the time in the 1960s with 'vascular haemophilia'. Inherited bleeding disorder was suspected early on, as an older sister died due to a bleeding complication at the age of 2 years. Type 3 VWD diagnosis was confirmed in the 1970s. The patient received cryoprecipitate for ovarian cyst bleeds at the age of 20 and 21 , and prior to an appendectomy at the age of 30 without complications. Alloantibody first appeared when the patient was giving birth at the age of 35 . At the time, therapy with cryoprecipitate was initially effective and continued for 10 days postpartum. However, at 8 days postpartum, following cryoprecipitate infusion, she had an allergic reaction with rash and fever. Simultaneously, VWF response in the laboratory vanished, but without haemostatic problems. Two years later, the next delivery was handled with plasma-derived VWF/FVIII concentrate (pdVWF/FVIII, 2.4:1 ratio, Haemate ${ }^{\circledR}$, CSL Behring) without allergic reactions. Again, at 6 days postpartum, VWF response after replacement disappeared, but haemostasis was conserved by increasing Haemate ${ }^{\circledR}$ doses. At the age of 41 , a tooth extraction was managed successfully by a single Haemate $\AA$ infusion.

The first severe $\mathrm{GI}$ bleeding episode occurred at the age of 46 in a local hospital prior to patient referral into our centre. Due to melaena with anaemia and with a family history of colorectal cancer, the patient underwent a colonoscopy. Tubulovillous adenoma with mild dysplasia was resected under Haemate ${ }^{\circledR}$ combined with a monoclonal antibody-purified pdFVIII to increase FVIII content (Amofil®, manufactured with the method M, Sanquin) prophylaxis.
This treatment approach had been successful in managing another Finnish type 3 patient with alloantibodies. Following the colonoscopy, the patient developed prolonged GI bleeding, receiving replacement with Haemate ${ }^{\circledR}$ and Amofil ${ }^{\circledR}$ concentrates, and red blood cell (RBC) transfusions. The bleeding ceased after 21 hospital days. Subsequently, she was referred to our comprehensive care centre for regular follow-up.

Laboratory results at our centre demonstrated absent VWF (VWF:Ag and VWF:RCo below the sensitivity of these assays) and low FVIII (2 IU/dL). DNA analysis of the VWF revealed a homozygous nonsense null mutation c.4975C > T (p.R1659X) in exon 28. ${ }^{4}$ During 3 years of follow-up, the patient had only minor bleeding problems and managed with tranexamic acid (TXA). She had stable hypertension on a diuretic, and menorrhagia was controlled with oestrogen therapy.

At the age of 49, a control colonoscopy was performed in our hospital, leading to the severe bleeding episode reported here. The procedure was decided to be managed with a different pdVWF/ FVIII concentrate than previously, Wilate ${ }^{\circledR}$ (Octapharma), due to the higher FVIII ratio (VWF/FVIII 1:1). The patient received a dose of $40 \mathrm{IU} / \mathrm{kg}$ of Wilate ${ }^{\circledR}$ prior to the colonoscopy on day 1 (Figure 1), during which 6 minor polyps (later confirmed benign hyperplastic) were resected with satisfactory primary haemostasis. Wilate ${ }^{\circledR}$ (20 IU/kg) replacement therapy was continued twice daily for 2 postoperative days with good laboratory response. On day 3 , the patient was discharged from the hospital without bleeding signs.

However, on her way home at the train station, an acute lower $\mathrm{Gl}$ bleed started, and she returned to the hospital in the evening of day 3. The Wilate ${ }^{\circledR}$ therapy was restarted with a bolus of $40 \mathrm{IU} / \mathrm{kg}$, followed by $20 \mathrm{IU} / \mathrm{kg}$ every 8 hours. During hospital days 3 to 6, despite good VWF and FVIII levels, the GI bleed persisted. In addition to factor concentrate, she received daily RBC transfusions aiming at haematocrit above $30 \%$, and platelet transfusions to substitute her defective platelet VWF.

On day 7 , the response to therapy was suddenly lost (no measurable VWF or FVIII, Figure 1). At the same time, the GI bleeding worsened, with severe melaena 10 times and $1700 \mathrm{~mL}$ daily. This was considered to represent the appearance of a VWF inhibitor, and the patient was transferred to the intensive care unit. Treatment with rFVIla (NovoSeven ${ }^{\circledR}$, Novo Nordisk, at $9.6 \mathrm{mg}[109 \mathrm{\mu g} / \mathrm{kg}]$ ) every 2 hours was initiated to replace Wilate ${ }^{\circledR}$. To achieve local 


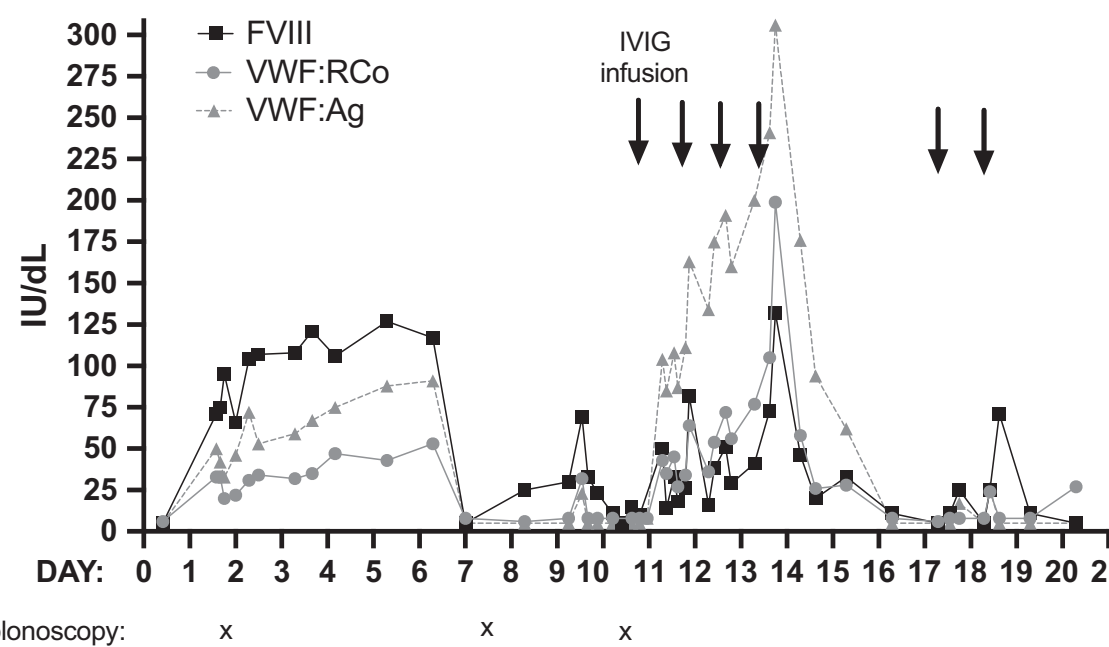

colonoscopy:
GI bleed:
epistaxis:
pdVWF/FVIII ${ }^{1}$
rFVIIa
pdVWF/FVIII
pdFVIII

haemostasis, a control colonoscopy was performed on day 7, discovering bleeding from multiple biopsy sites. In a difficult procedure with poor local haemostasis, these sites were treated with 7 clips. On day 8 , with the uncontrolled GI bleed continuing, a combination therapy of Haemate ${ }^{\circledR}$ (increasing doses from 27/11 to 81/33 IU/ $\mathrm{kg}$ ) and Amofil ${ }^{\circledR}(33 \mathrm{lU} / \mathrm{kg}$ ) was initiated, with the experience that this treatment had resolved the previous GI bleeding episode. Haemate ${ }^{\circledR}$ and Amofil ${ }^{\circledR}$ were administered 4-6 times daily, alternating with rFVIIa at 6-8 times daily. RBC transfusions were continued (daily 4-6 units), and platelets and fresh frozen plasma (Octaplas ${ }^{\circledR}$, Octapharma) were also administered. She tolerated therapies without allergic or thrombotic reactions. Transient VWF response was observed day 9 , but the bleed continued.

On day 10 , a new control colonoscopy was performed, and a single active site was clipped. However, haemoglobin levels were not maintained, and on day 11, without measurable response to VWF or FVIII, we infused IVIG at $1 \mathrm{~g} / \mathrm{kg}$ ( $90 \mathrm{~g}$, Nanogam ${ }^{\circledR}$, Sanquin). Importantly, VWF and FVIII levels were immediately restored in a few hours after the infusion, and rFVIla was halted (Figure 1). The GI bleed finally ceased, and the patient was transferred back to the regular ward. Therapy with Haemate $\AA$ and Amofil $\AA$ was continued, and IVIG administered every 24 hours 4 times. After the fourth infusion, when VWF:RCo suddenly reached 200 IU/dL, IVIG was stopped. The positive effect of IVIG infusions on VWF and FVIII lasted for 2 days.

Although the $\mathrm{Gl}$ bleed stopped, hospitalization was prolonged due to epistaxis occurring on day 13 , which was treated by posterior tamponation. The epistaxis recurred after the removal of the tamponade on day 17, and two more IVIG infusions were administered. The impact on VWF and FVIII levels was again immediate and enough to control the bleed. Finally, the patient was discharged from the hospital at day 20.
FIGURE 1 Timelines demonstrating the treatment of a life-threatening GI bleed of type 3 VWD patient with anti-VWF alloantibodies. The patient underwent an elective colonoscopy with biopsy on day 1 , leading to severe gastrointestinal (GI) bleeding complication (day 3-11). Following intravenous immunoglobulin (IVIG) treatment (arrows), the bleed resolved, and response to VWF treatment was achieved. Epistaxis further prolonged the hospital stay and repeated infusions of IVIG on days 17 and 18 again restored VWF and FVIII levels. VWF:Ag = VWF antigen, $\mathrm{VWF}: \mathrm{RCo}=\mathrm{VWF}$ ristocetin cofactor activity, $\mathrm{pd}=$ plasma-derived $\mathrm{VWF} /$ FVIII, pdVWF $/ F V I I I^{1}=$ Wilate ${ }^{\circledR}$, pdVWF $/$ $\mathrm{FVIII}^{2}=$ Haemate ${ }^{\circledR}$
The bleeding episode demonstrated a classical outcome of an anti-VWF antibody upon re-exposure to a VWF concentrate, with the neutralizing antibody developing at 6 days after initiating the treatment. In a sample obtained a few weeks after the acute bleeding episode, no VWF antibody could be traced (ELISA-based polyclonal anti-human IgG antibody assay, kind assessment by $\mathrm{Dr}$ Marc Jacquemin). Since the bleeding episode, the patient has experienced only minor bleeds, mainly epistaxis, treated with TXA. An anti-VWF:CB antibody titre of $5 \mathrm{BU} / \mathrm{mL}$, without anti-VWF IgG or IgM antibodies, was measured as part of the International Registries and Inhibitor Prospective (3WINTERS-IPS) study, still some years after the last exposure to VWF-containing replacement therapy. Currently, the lack of general consensus on the method of measuring anti-VWF antibodies complicates the diagnostics. ${ }^{1}$ Recently, due to epistaxis, the patient received Haemate ${ }^{\circledR}$ in a local hospital and developed shortness of breath, dizziness and itchiness in the throat postinfusion, resolving after discontinuation of the treatment.

There are previous reports of using immuno-modulative treatment as part of immunotolerance induction regimens in paediatric type 3 VWD patients, including the use of IVIG, rituximab and mycophenolate mofetil. ${ }^{5,6}$ However, according to our knowledge, our case report describes for the first time, how IVIG therapy preceding pdVWF/FVIII infusion helped to resolve an acute bleed in a type 3 VWD patient with anti-VWF antibodies. Similar approach has been reported in AVWS mainly in cases of monoclonal gammopathy, whereas our patient had normal serum protein electrophoresis. Possible mechanisms of action for IVIG include elimination of circulating immune complexes, inhibitory effect on the antibody-producing cells or preventing the clearance of inhibitor-VWF complex by blocking Fc receptors, but other mechanism may also be involved. ${ }^{7}$ 
To date, recommendations on the treatment of VWD patients who develop anti-VWF antibodies are based on case reports and expert opinions. As it is unknown which patients with anti-VWF alloantibodies will develop severe allergic reactions, a review article suggested avoiding VWF-containing concentrates. ${ }^{1}$ Both rFVIII and rFVIla have been used to treat bleeds and manage surgery among these patients. $^{8,9}$ However, alternative treatment options should be also considered, and VWF-containing products are also used. ${ }^{10}$ rFVIla was not optimally effective in our case. The use of $r F V I I I$ alone at high doses of continuous infusion corrects FVIII levels. As expert opinions suggest that the haemostatic control in VWD is more dependent on FVIII than VWF activity levels, treatment with rFVIII appears as a possible future strategy for treating bleeds in our patient.

\section{ACKNOWLEDGEMENTS}

We would like to acknowledge and thank the patient for allowing us to report her story. We would also like to acknowledge Dr. Marc Jacquemin on the VWF antibody assessment, and the nurses in our unit for their skilful help. We are deeply grateful to Professor Augusto Federici for his contribution by reviewing our manuscript.

\section{DISCLOSURES}

VN reports receiving a lecture honorarium from CSL Behring and support to participate in international meetings by CSL Behring and Octapharma. EL participated in industry-sponsored clinical research by Octapharma and has received fees for consultations and speaking as well as support for attending a symposium from Octapharma, Sanquin and CSL Behring. TS received a non-restricted research grant from CSL Behring, lecture honorarium from Sobi and Sanquin, and support to participate in international meetings by CSL Behring and Octapharma. AM has no interests which might be perceived as posing a conflict or bias. RL has been in the global advisory board of Shire, Nordic advisory board of CSL Behring, and speaker for Sanquin and has received support to participate in international meetings by CSL Behring and Shire.

\section{AUTHOR CONTRIBUTION}

VN collected the data with the assistance of AM. VN wrote the first version of the manuscript. EL, AM, TS and RL contributed to the treatment of the patient and analysis of the case. All authors approved the final version of the manuscript.

$$
\begin{array}{r}
\text { Vuokko Nummi }{ }^{1,2} \text { iD } \\
\text { Elina Lehtinen }^{2} \\
\text { Anne Mäkipernaa }
\end{array}
$$

Timea Szanto 3 iD

Riitta Lassila ${ }^{1,2}$

${ }^{1}$ Faculty of Medicine, University of Helsinki, Helsinki, Finland

${ }^{2}$ Coagulation Disorder Unit, Department of Hematology and Comprehensive Cancer Center, Helsinki University Hospital, Helsinki,

Finland

${ }^{3}$ Coagulation Disorder Unit, Department of Clinical Chemistry, HUSLAB Laboratory Services, Helsinki University Hospital, Helsinki, Finland

Correspondence

Riitta Lassila, Coagulation Disorders Unit, Department of Hematology and Comprehensive Cancer Center, Laboratory Services, University of Helsinki, Helsinki University Hospital, P.O. Box 372, 00029 HUS,

Helsinki, Finland.

Email: riitta.lassila@hus.fi

\section{ORCID}

Vuokko Nummi iD https://orcid.org/0000-0002-5134-7288

Timea Szanto (iD https://orcid.org/0000-0001-7006-6564

\section{REFERENCES}

1. James PD, Lillicrap D, Mannucci PM. Alloantibodies in von Willebrand disease. Blood. 2013;122:636-640.

2. Mannucci PM, Tamaro G, Narchi G, et al. Life-threatening reaction to factor VIII concentrate in a patient with severe von Willebrand disease and alloantibodies to von Willebrand factor. Eur J Haematol. 1987;39:467-470.

3. Tiede A, Rand JH, Budde U, Ganser A, Federici AB. How I treat the acquired von Willebrand syndrome. Blood. 2011;117(25):6777-6785.

4. Jokela V, Lassila R, Szanto T, et al. Phenotypic and genotypic characterization of 10 Finnish patients with von Willebrand disease type 3: discovery of two main mutations. Haemophilia. 2013;19:e344-e348.

5. Pergantou $\mathrm{H}$, Xafaki P, Adamtziki E, Koletsi $\mathrm{P}$, Komitopoulou A, Platokouki $\mathrm{H}$. The challenging management of a child with type 3 von Willebrand disease and antibodies to von Willebrand factor. Haemophilia. 2012;18:e66-e67.

6. Berntorp E, Ågren A, Aledort L, et al. Fifth Åland Island conference on von Willebrand disease. Haemophili. 2018;4:5-19.

7. Federici AB. Use of intravenous immunoglobulin in patients with acquired von Willebrand syndrome. Hum Immunol. 2005;66:422-430.

8. Mannucci PM, Federici AB. Antibodies to von Willebrand factor in von Willebrand disease. Adv Exp Med Biol. 1995;386:87-92.

9. Ciavarella N, Schiavoni M, Valenzano E, Mangini F, Inchingolo F. Use of recombinant factor VIla (NovoSeven) in the treatment of two patients with type III von Willebrand's disease and an inhibitor against von Willebrand factor. Haemostasis. 1996;26(Suppl 1):150-154.

10. Jenkins S, Carcao M, Bouskill V. Type 3 VWD and an inhibitor to VWF: Challenges in diagnosis. J Haem Pract. 2016;3(2):1-3. 